\title{
Н.И. Шитова
}

\section{К ВОПРОСУ О ВЫЯВЛЕНИИ НОВЫХ ПИСЬМЕННЫХ ИСТОЧНИКОВ ПО ТРАДИЦИОННОЙ КУЛЬТУРЕ (ПО МАТЕРИАЛАМ РУССКИХ ГОРНОГО АЛТАЯ) ${ }^{1}$}

\begin{abstract}
Статья посвящена обобщению опыта работы автора по выявлению в ходе этнографических исследований русских Горного Алтая новых письменных источников. Показаны различные пути обнаружения рукописей, мемуаров, записей фольклорного содержания. Освещено значение этих новых источников для изучения культуры и этнической истории русских Горного Алтая.

Ключевые слова: русские, традиционная культура, этническая история, нарративные источники, полевые этнографические исследования, Горный Алтай.
\end{abstract}

В настоящее время в связи с уходом из жизни представителей самого старшего поколения при исследовании традиционной культуры и этнической истории все большее значение приобретает выявление новых письменных источников. В период с 2007 по 2014 г. автором зафиксирован ряд подобных источников, часть из которых опубликована. В настоящей работе мы попытаемся показать пути, способы обнаружения этих письменных источников в ходе полевых исследований, а также обозначить их значение для изучения истории и культуры региона. Освещение этих вопросов, на наш взгляд, может представлять интерес для исследователей при разработке опросников, методов сбора полевых материалов и в конечном счете способствовать обнаружению новых источников.

Один из распространенных путей знакомства с рукописным наследием крестьян - это когда сам автор показывает исследователю свои записи, дополняя их содержание воспоминаниями, сообщениями. Так мы познакомились с мемуарами жительницы с. Ильинка Т.А. Шевелевой, написанными в нескольких тонких ученических тетрадках, сшитых вместе, общим объемом 68 л. [1].

Как рассказывает Татьяна Александровна, мысль написать свои воспоминания не возникла у нее случайно. Еще в детстве она столкнулась с примером письменного изложения событий, связанных с жизнью одного из ближайших родственников по линии отца, скорее всего его брата: Я была маленькая и не читала ее. А так помню по рассказам отияа, как они жили. Со временем были богатые люди. Не послушался отияа, и он его отдал в армию на 20 лет. Вот так он служил и писал (полевые материалы автора, далее в тексте - ПМА, 2014). В семье была некая тетрадка с воспоминаниями, которую дети, будучи еще в несознательном состоянии, уничтожили: Тятя дал нам тетрадь, род-

\footnotetext{
${ }^{1}$ Работа выполнена при поддержке РГНФ, проекты №14-11-04001 «Русские среднегорной зоны Горного Алтая: этнокультурная специфика»; №15-01-00453 «Этнокультурные ландшафты Южной Сибири. Историческая динамика и сравнительный анализ (конец XIX - начало XXI в.)».
} 
ственники его тоже писали. Он нам дал, мы изорвали как попало (ПМА, 2014). То есть Татьяна Александровна начала работать над своими воспоминаниями, с одной стороны, следуя семейному примеру, с другой - стремясь исправить совершенное еще в детстве по неразумию уничтожение семейных записей. Это представитель старшего поколения, который сознательно относится к историческим сведениям о своей малой родине и понимает их значение для следующих поколений: Я думаю, я напишу, чтоб никто не рвал. Дам детям, чтобы помнили и знали (ПМА, 2014).

Эта рукопись - ценный источник по истории села в советский период. При этом ее содержание иллюстрирует трудность, с которой автор столкнулся при сборе полевых этнографических материалов на территории Шебалинского района Горного Алтая - отсутствие у большинства информантов сведений об истории переселения семей в Горный Алтай и первичного хозяйственного освоения территории. Отметим, что крестьянские нарративы, даже если с первого взгляда в них отсутствует информация этнокультурного характера, заслуживают внимательного изучения. Сам факт того, что человек приступил к написанию мемуаров, может иметь корни в семейных традициях, как в случае с сочинением Т.А. Шевелевой. Также отсутствие определенного пласта информации - в нашем случае об истории семьи - может являться маркером ситуации, характерной для района исследования в целом. Некоторые эпизоды, изложенные как бы невзначай, могут нести информацию об отдельных элементах традиционной культуры, например о бытовании православных традиций.

В 2014 г. мы получили возможность познакомиться с интереснейшим источником по фольклору русского населения Горного Алтая, и в этом нам помог совет односельчан. Жительница с. Черга Шебалинского района Степанида Дорофеевна Дьяченко, 1933 г.р., много лет собирала частушки, которые знала сама и слышала в селе. В итоге ею было записано более тысячи частушек. Это две общие тетради. Тетрадь №1 содержит 49 листов, в которой записано 733 частушки [2]. Тетрадь №2 заполнена не полностью, записи содержатся на 26 листах и содержат 390 частушек [3]. Из записей в тетради №2 следует, что они были сделаны в 1985 г., судя по наполненности, тетрадь № 1 была заполнена раньше.

Полевые материалы автора свидетельствуют о том, что в песенном репертуаре наиболее популярными были частушки: Особенно частушики, песни не пели. Среди частушек, собранных С.Д. Дьяченко, встречаются самые разные, как широко распространенные, так и носящие местный колорит, сочиненные или переделанные в самой Черге, а также относящиеся к разным периодам вплоть до перестройки. Сама собирательница подразделяет частушки на «постные» и «молосные» и поясняет это деление примерами (ПМА, 2014, с. Черга). Постная частушка:

Уж частушечки я петь

Научилась просто

A теперь я петь их буду

Лет до 90.

Молосная частушка:

На заваленке лежала

Шубой одевалася

Никому я не давала

Куда шерсть девалася. 
Ценность этого источника заключается в том, что он дает представление о местном, локальном репертуаре, бытовавшем в Горном Алтае.

В случае, если пожилые люди чувствуют себя плохо, общаются только с самыми близкими людьми, записи крестьян могут показать исследователю их дети или другие родственники. О том, что одна из старейших жительниц с. Чоя Клавдия Ивановна Усова хранит мемуары отца, Ивана Лупоновича Нохрина, автору рассказали ее односельчане. Поскольку в настоящее время имеется возможность побеседовать с представителями поколения 19201930-х гг. рождения, воспоминания И.Л. Нохрина, 1900 г. р., являются ценным источником. Особый интерес представляет повествование о переселении семьи в Горный Алтай и ее обустройстве на новом месте, а также упоминания о первых русских жителях в этих местах. Заметим, что в рукописях содержатся также воспоминания о становлении советской власти, образовании колхоза, о сталинских репрессиях. Мемуары И.Л. Нохрина состоят из следующих произведений, написанных в 1974 г.: «На память моим поколениям. Мое происхождение. Биография» [4], «История с. Чоя Майминского района Горно-Алтайской автономной области» [5].

В с. Ильинка зафиксированы записи Зинаиды Ивановны Колпаковой (19402011 гг.), посвященные народной медицине. Их предоставила для исследования дочь Зинаиды Ивановны, Людмила. Показала их нам женщина после нескольких часов общения, получше познакомившись с участниками исследовательской группы и убедившись предварительно, что эта часть традиционной культуры (народная медицина) интересует нас так же, как традиционная одежда и рукоделия. Этот источник можно подразделить на две основные части: записи заговоров и записи рецептов настоев, мазей и прочих способов лечения народными методами. Заговорам посвящены: два фрагмента ученических тетрадей, в одном из которых заговоры пронумерованы (объем 23 с.) [6], в другом - нет (7 с.) [7], также отдельные листы с одним или несколькими заговорами (26 л.) [8]. Это заговоры от различных болезней людей, иногда скота, также направленные на конкретные нужды (например, мир в семье, успехи в пчеловодстве или «чтобы никто не обидел»). Заговоры направлены против следующих болезней: лихоманка, лихорадка, от проклятых болезней, от кровотечения, от младенки, от рожи, от чирья, от испуга, от уроков, от водянки, от болезней горла, от зубной боли, от боли в пояснице, от ячменя и пр.

Рецепты записаны на одном фрагменте ученической тетради [9], а также на отдельных листах [10]. Способы лечения народными средствами направлены на исцеление от следующих заболеваний: от геморроя, ангины, от нарывов и опухолей, от бронхита и кашля, от насморка, от ран и порезов, от бссонницы и пр. Можно предположить, что ряд из них переписан из различных источников (как собственно бытующих народных рецептов, так и опубликованных).

Заметим, что зачастую от информантов мы слышали об умении их родственников излечивать с помощью заговоров, а также настоев и мазей ряд болезней. Но при этом и тексты заговоров, и информация о совершавшихся действиях были утрачены. Такой источник, как записи 3.И. Колпаковой, уникален по нескольким причинам. Во-первых, достоверно известно, что автор записей занималась целительством с молоду и научилась этому у своей мате- 
ри, т.е. записи составлены носителем традиционной культуры, получившим свои знания традиционным способом. Во-вторых, это комплексный источник, в котором представлен основной набор применяемых народом заговоров. В-третьих, помимо текста заговора, в ряде случаев приведено описание действий целительницы, что само по себе представляет особый научный интерес и позволяет рассмотреть это явление как сочетающее в себе ритуал и слово. Также в источнике отчетливо прослеживается сочетание применения слова (заговора) и всевозможных лекарственных народных средств. Можно проследить некоторую закономерность - заговоры более направлены на избавление от психических расстройств и сопряженных с ними заболеваний, а вот для лечения насморка, кашля, ран предусмотрены, прежде всего, народные лекарственные средства.

Наиболее долгим и в то же время, интересным был процесс обнаружения рукописного наследия уймонского старообрядца Тимофея Филипповича Бочкарева, 1917 г.р. Исследованию его рукописей в контексте истории и культуры старообрядцев Уймона посвящена монография автора статьи [11]. Первым зафиксированным письменным источником стала рукопись старообрядца, позже обозначенная нами как рукопись №1 [12]. Источник был обнаружен в ходе опроса местных жителей об истории семьи, о местах выхода старообрядческих первопоселенцев Уймонской долины Горного Алтая. От одного из собеседников был получен нестандартный, более подробный ответ. Вслед за этой информацией последовал наш вопрос об источнике этих знаний, в ответ на который наш собеседник сообщил о некогда существовавшем дневнике старообрядческого первопроходца-ходока Исаака Бочкарева. При прибытии на место хранения источника в другое село было выяснено, что эта рукопись представляет собой сочинение самого Тимофея Филипповича, пытавшегося по памяти изложить этот дневник. В это же время нам показали другие 2 тетради, содержимое которых обозначено позже как рукопись Т.Ф. Бочкарева №4 [13].

Рукописи №2 [14] и №3 [15] Т.Ф. Бочкарева были обнаружены как бы случайно. В ходе экспедиции 2007 г. автор допустила следующую ошибку - сразу не сняла копию с показанной старообрядцами рукописи №4. Заметим, что позже, через 3 года, при фиксации этой рукописи возникли трудности: если в прошлый раз хранитель источников шел на контакт, то в этот раз едва удалось убедить его показать эти же тетради. С другой стороны, эта оплошность привела к тому, что были найдены рукописи № 2 и 3 Т.Ф. Бочкарева, о существовании которых не подозревали самые близкие родственники, в том числе хранитель рукописей № 1 и 4. Это произошло следующим образом: так как рукопись №4 не была зафиксирована, автор статьи обратилась за помощью к внучкам старообрядца - автора мемуаров и попросила привезти эти тетради. Вместо ожидаемой рукописи были найдены и привезены неизвестные ранее рукописи (№ 2 и 3 ).

Рукопись № 1 состоит из 44 страниц, пронумерованных автором, рукопись № 2 - из 57 листов, пронумерованных автором (113 страниц). Обе рукописи написаны в ученических тетрадях в клетку с расчерченными автором полями. Оба труда являются попытками, предпринятыми Т.Ф. Бочкаревым в разное время, изложить по прошествии многих лет сведения по истории семьи Бочкаревых. Эти знания Тимофей Филиппович получил в юности, когда читал «тетрадь отца», Филиппа Максимовича Бочкарева. «Тетрадь отса» была уничтожена во время репрессий $1930-$ х гг. О том, что такой источник 
существовал, родственники Т.Ф. Бочкарева рассказывают следующим образом: Была книжка, когда он (Т.Ф. Бочкарев. - Н.Ш.) ещзе маленький был. Он писал, сам Исаак, который шел хребтами (ПМА, 2011 г., с. Мульта, В.М. Кузнецова, 1940 г.р.). Видимо, это были подлинные исторические записи, сделанные главным героем рукописей - Исааком Бочкаревым или же копии этих записей, сделанные самими старообрядцами. О том, что во время своего путешествия из Европейской России в Горный Алтай Исаак Бочкарев ежедневно вел дневник, сообщается в рукописи № 2 .

Рукопись № 2 по объему приблизительно в 2 раза больше рукописи № 1, поэтому отдельные события в ней описаны более тщательно. Так, подробнее повествуется о причинах переезда старообрядческих семей из района Подмосковья («две версты от Москвы») к р. Керженец, охарактеризованы хозяйственные занятия старообрядцев во время проживания в этих местах. Особое внимание уделено особенностям труда и быта Исаака Бочкарева во время первой зимовки в алтайских горах. Подробнее повествуется о последующем групповом переселении старообрядцев в Уймонскую долину, специфике обустройства на новом месте. Рукопись № 2 отличается также тем, что в ней описано еще одно путешествие поездка Исаака с братьями в Москву за невестами и их путь назад. Кроме того, в этой рукописи упоминаются события, связанные с последующим приездом в Уймонскую долину старообрядцев Ленских, Железновых.

Рукопись № 3 первоначально охватывала период с 1929 по 1944 г. Вероятно, самим автором из сочинения была удалена часть листов. Рукопись № 3 содержит 61 лист, пронумерованный автором (т.е. 122 страницы), и охватывает период с 1929 по 1937 г. В источнике описана старообрядческая повседневность, эпизоды Гражданской войны в Горном Алтае, бесправное положение крестьянства, особенности жизни спецпереселенцев и т.п.

Рукопись № 4 состоит из двух тетрадей и посвящена воспоминаниям об аресте, тюрьме и жизни в сталинских лагерях. Нумерация листов первой тетради двойная. Она содержит 39 листов, пронумерованных автором, начиная с первого листа. При этом имеется еще и постраничная нумерация: номера стоят в верхних внешних углах страниц, начиная с 89-й страницы и заканчивая 176-й страницей. Здесь описаны события 1937-1938 гг. Наличие двойной нумерации страниц дает основание предполагать, что этой тетради предшествовала еще одна, с нумерацией до 88-й страницы, которая в настоящее время не обнаружена. Очевидно, что это не рукопись № 3, поскольку в ней пронумерованы только листы и последние записи этой рукописи по содержанию пересекаются с начальным содержанием первой тетради рукописи № 4. Тетрадь № 2 рукописи № 4 начинается с 40-го и заканчивается 85-м листом. В тетради описаны события 1939-1942 г. Совпадение авторской нумерации листов в тетрадях и хронологическая последовательность изложения позволяют рассматривать их содержание как одну рукопись № 4. В рукописи № 4 присутствует также вкладка из трех листов в линию формата A4, озаглавленная как «Второе путешествие». Содержание этих листов посвящено событиям мая - июня 1944 г., текст не является законченным - видимо, остальные листы с этой частью мемуаров потеряны.

Рукописи № 3 и 4 ценны тем, что в контексте описания событий автор органично излагает в тексте емкие старообрядческие формулировки, а также приводит ряд ситуаций, в которых четко представлены особенности мировоззрения 
уймонских старообрядцев: это отношение к окружающей природной среде и животным, самоидентификация с традиционными нормами поведения, осмысление природы человека. Особое место в мировоззренческом аспекте анализа содержания исследуемых рукописей занимает тема силы духа человека, позволяющей выжить в самых нечеловеческих условиях сталинских тюрем и лагерей.

Помимо такого объемного комплекса старообрядческих рукописей, зафиксированы также небольшие по объему записи, содержание которых представляет большой интерес для исследования старообрядческой культуры. К таким источникам можно отнести и записку о правилах старообрядческого погребения, составленную Н.Л. Казаниной, жительницей с. Чоя, хранящуюся в погребальном узелке с комплексом погребальной одежды [16]. В узелке хранится комплекс погребальной одежды, который состоит из савана, рубахи, платочка, наволочки (изготовленных из покупной ткани типа мешковины), носков, а также ладана, пеньковой веревки, лестовки, подручника, венчика и нательного креста. Погребальный комплекс сопровождается запискойпамяткой, представляющей собой краткую инструкцию для родственников о старообрядческих правилах погребения с описанием последовательности действий по обмыванию и облачению покойного. Необходимость составления пожилой женщиной такой записки обусловлена ухудшающимся состоянием здоровья и отсутствием единоверцев.

В краткой записке Н.Л. Казаниной изложены важные этнографические особенности ранее существовавшего в с. Чоя старообрядчества, от которого в настоящий момент осталась последняя пожилая представительница. Приготовление усопшего к погребению предписано начинать с сотворения молитвы и троекратного крестного знамения. Затем следует покадить домовину, произнеся молитву «Святый Боже, Святый Крепкий», с произнесения этой же молитвы предписано начинать обмывание. Интересной особенностью является представление о необходимости изготовления сосуда для обмывания умершего из овощей - свеклы, редьки или брюквы, из которых вырезается серединка. Заканчивается эта записка тем, что все предметы обмывания, а также нательный крест усопшей предписывается утопить. Заметим, что специфика этого источника такова, что, чтобы не осквернить мирскими руками содержание погребального комплекса, автор статьи не брала записку в руки, не фотографировала ее, а записала точно со слов дочери старообрядки.

В заключение отметим, что новые письменные источники были выявлены следующими путями:

- предоставление самим нашим собеседником, информантом своих мемуаров для изучения локальной истории и культуры;

- при помощи сообщения односельчан о том, что кто-то хранит рукописи, воспоминания, собирает фольклор;

- в ходе изучения других аспектов традиционной культуры, наладившихся вследствие общения на этой почве добрых отношений с информантами, понимание ими искренней заинтересованности исследователя в изучаемой им проблеме, убежденность в его профессионализме;

- в результате беседы с информантами (свободное интервьюирование в соответствии с опросником по теме этнографического исследования) и использования дополнительных вопросов; 
- в результате поиска (вторичного) уже обнаруженного ранее источника;

- в ходе осмотра современных предметов традиционной культуры, имеющих функциональное значение.

Обнаруженные различными способами письменные источники разнообразны и представляют интерес для изучения многих сторон традиционной материальной и духовной культуры, а также этнической и локальной истории как православного, так и старообрядческого русского населения Горного Алтая.

\section{Литература}

1. Шевелева Т.А. Воспоминания. Рукопись. с. Ильинка. 68 л.

2. Дьяченко С.Д. Тетрадь № 1. Рукопись. с. Черга. 49 л.

3. Дьяченко С.Д. Тетрадь № 2. Рукопись. с. Черга. 26 л.

4. Нохрин И.Л. На память моим поколениям. Мое происхождение. Биография. С. Чоя, 1974. 7 л. // Шитова Н.И. Русские низкогорной зоны Горного Алтая (XX-начало XXI вв.). Горно-Алтайск, 2014. С. 178-183.

5. Нохрин И.Л. История с. Чоя Майминского района Горно-Алтайской автономной области. Чоя, 1976. 10 л. // Шитова Н.И. Русские низкогорной зоны Горного Алтая (XX - начало ХХІ вв.). Горно-Алтайск, 2014. С. 184-191.

6. Колпакова 3.И. Тетрадь № 1. Рукопись. С. Ильинка. 23 с.

7. Колпакова 3.И. Тетрадь № 2. Рукопись. С. Ильинка. 7 с.

8. Колпакова 3.И. Фрагмент № 1. Рукопись. С. Ильинка. 26 л.

9. Колпакова 3.И. Тетрадь № 3. Рукопись. С. Ильинка. 10 с.

10. Колпакова 3.И. Фрагмент № 2. Рукопись. С. Ильинка. 24 л.

11. Шитова Н.И. Рукописи старообрядца Т.Ф. Бочкарева в контексте истории и культуры старообрядцев Уймона (XVIII-XXI вв.). Горно-Алтайск : ГАГУ, 2013. 360 с.

12. Бочкарев Т.Ф. Рукопись № 1 // Шитова Н.И. Рукописи старообрядца Т.Ф. Бочкарева в контексте истории и культуры старообрядцев Уймона (XVIII-XXI вв.). Горно-Алтайск, 2013. С. 98-115.

13. Бочкарев Т.Ф. Рукопись № 2 // Шитова Н.И. Рукописи старообрядца Т.Ф. Бочкарева в контексте истории и культуры старообрядцев Уймона (XVIII-XXI вв.). Горно-Алтайск, 2013. С. 116-165.

14. Бочкарев Т.Ф. Рукопись № 1 // Шитова Н.И. Рукописи старообрядца Т.Ф. Бочкарева в контексте истории и культуры старообрядцев Уймона (XVIII-XXI вв.). Горно-Алтайск, 2013. С. 166-242.

15. Бочкарев Т.Ф. Рукопись № 1 // Шитова Н.И. Рукописи старообрядца Т.Ф. Бочкарева в контексте истории и культуры старообрядцев Уймона (XVIII-XXI вв.). Горно-Алтайск, 2013. C. 243-306.

16. Казанина Н.Л. [Памятка] 1 л. // Полевые материалы автора, 2012 г. с. Чоя.

Shietova Natalja I. Gorno-Altaisk State University (Gorno-Altaisk, Russian Federation). E-mail: natalJa.sni2011@yandex.ru. DOI 10.17223/22220836/19/7

ABOUT NEW WRITTEN RESOURCES ON TRADITIONAL CULTURE (WITH REFERENCE TO THE RUSSIAN POPULATION OF GORNY ALTAI)

Key words: Russian population, traditional culture, ethnic history, written reseources, Gorny Altai (the Altai Republic, Russia).

Today, when the oldest representatives of our generation leave this world, finding new written sources to conduct further research of the traditional culture and ethnic history has even a greater value. In the period since 2007 till 2014 the author has found a number of new written works, part of which has been published. We try to show ways and methods for finding new sources in field work of a researcher and describe their meaning in the study of the history and culture of a region. The work on these tasks, as we believe, may be found useful for other researchers, who work out questionnaires and methods of collecting field materials. As a result our work facilitates finding new resources.

The author has registered the following written works on the traditional culture:

- memoir notes of T. A. Shevelyova, a resident of Ilyinka Village, written in a few school notebooks and laced together as one set;

- a book with chastushki, which is two exercise books, written by S. D. Dementyeva from Cherga Village; 
- memory notes on separate sheets of paper, written by I. L. Nohrin, a farmer from Choya Village; born in 1900;

- notes about medicine by Z. I. Kolpakova from Ilyinka Village that have been found in the form of fragments of texts in a school note book and on sheets of paper. This work can be divided into 2 parts: texts with spells and texts with recipes of herbal medicinal preparations, ointments and other traditional ways for treatment;

- a complex of manuscripts by T. F. Bochkaryov from Multa Village in five note books: Manuscript 1 and 2 tell a family legend about I. Bochkaryov, a traveler and an Old Believer, and about Old Believers in Gorny Altai, who moved to another settlement; Manuscript 3 and 4 contain notes done by some Old Believers about their life in the period from 1929 to 1946 ;

- small-volumed notes, for example, about rules of a burial procedure of Old Believers, written by N. L. Kazanina from Choya Village and found as part of burial clothing .

As a conclusion it is worth noting that new written sources have been found by means of these ways:

- an interviewee himself or herself shared his or her notes for the study of regional history and culture;

- one of the residents in a village told us about a person who kept memoir notes, manuscripts, who collects folklore materials;

- in the course of other aspects of traditional culture; due to favorable relations between an researcher and an informant; as a result of people's understanding of sincere research work and professionalism of an interviewer.

\section{References}

1. Sheveleva, T.A. (n.d.) Vospominaniya [Memories]. [Manuscript] Il'inka.

2. D'yachenko, S.D. (n.d.) Tetrad' № 1 [Book № 1]. [Manuscript] Cherga.

3. D'yachenko, S.D. (n.d.) Tetrad' № 2 [Book № 2]. [Manuscript] Cherga.

4. Nokhrin, I.L. (2004) Na pamyat' moim pokoleniyam. Moe proiskhozhdenie. Biografiya. S. Choya, 1974 [For my generations to remember. My origin. Biography. Choi, 1974]. In: Shitova, N.I. (ed.) Russkie nizkogornoy zony Gornogo Altaya (XX-nachalo XXI vv.) [The Russians in the lowmountain area of the Altai Mountains (the 20th - early 21st centuries)]. Gorno-Altaysk. pp. 178-183.

5. Nokhrin, I.L. (2014) Istoriya s. Choya Mayminskogo rayona Gorno-Altayskoy avtonomnoy oblasti. Choya, 1976 [The history of Choi Village, Maima District, Gorno-Altai Autonomous Region. Choi, 1976]. In: Shitova, N.I. (ed.) Russkie nizkogornoy zony Gornogo Altaya (XX-nachalo XXI vv.) [The Russians in the low-mountain area of the Altai Mountains (the 20th - early 21st centuries)]. Gorno-Altaysk. pp. 184-191.

6. Kolpakova, Z.I. (n.d.) Tetrad' № 1 [Book № 1]. [Manuscript] Il'inka

7. Kolpakova, Z.I. (n.d.) Tetrad' № 2 [Book № 2]. [Manuscript] Il'inka.

8. Kolpakova, Z.I. (n.d.) Fragment № 1 [Fragment № 1]. [Manuscript] Il'inka.

9. Kolpakova, Z.I. (n.d.) Tetrad' № 3 [Book № 3]. [Manuscript] Il'inka.

10. Kolpakova, Z.I. (n.d.) Fragment № 2 [Fragment № 2]. [Manuscript] Il'inka.

11. Shitova, N.I. (2013) Rukopisi staroobryadtsa T.F. Bochkareva v kontekste istorii i kul'tury staroobryadtsev Uymona (XVIII-XXI vv.) [Manuscripts of an Old Believer T.F. Bochkarev in the context of the history and culture of Uimon Old Believers (the 18th - 21st centuries)]. Gorno-Altaysk: GAGU.

12. Bochkarev, T.F. (2013a) Rukopis' № 1 [Manuscript \# 1]. In: Rukopisi staroobryadtsa T.F. Bochkareva $v$ kontekste istorii $i$ kul'tury staroobryadtsev Uymona (XVIII-XXI vv.) [Manuscripts of an Old Believer T.F. Bochkarev in the context of the history and culture of Uimon Old Believers (the 18th - 21st centuries)]. Gorno-Altaysk: GAGU. pp. 98-115.

13. Bochkarev, T.F. (2013b) Rukopis' № 2 [Manuscript \# 2]. In: Rukopisi staroobryadtsa T.F. Bochkareva v kontekste istorii i kul'tury staroobryadtsev Uymona (XVIII-XXI vv.) [Manuscripts of an Old Believer T.F. Bochkarev in the context of the history and culture of Uimon Old Believers (the 18th - 21st centuries)]. Gorno-Altaysk: GAGU. pp. 116-165.

14. Bochkarev, T.F. (2013c) Rukopis' № 1 [Manuscript \# 1]. In: Rukopisi staroobryadtsa T.F. Bochkareva v kontekste istorii i kul'tury staroobryadtsev Uymona (XVIII-XXI vv.) [Manuscripts of an Old Believer T.F. Bochkarev in the context of the history and culture of Uimon Old Believers (the 18th - 21st centuries)]. Gorno-Altaysk: GAGU. pp. 166-242.

15. Bochkarev, T.F. (2013c) Rukopis' № 1 [Manuscript \# 1]. In: Rukopisi staroobryadtsa T.F. Bochkareva v kontekste istorii i kul'tury staroobryadtsev Uymona (XVIII-XXI vv.) [Manuscripts of an Old Believer T.F. Bochkarev in the context of the history and culture of Uimon Old Believers (the 18th - 21st centuries)]. Gorno-Altaysk: GAGU. pp. 243-306.

16. Kazanina, N.L. (2012) [Memo]. s. Choya. (In Russian). 